\title{
Babesiose cerebral em bovinos: 20 casos
}

\author{
Cerebral babesiosis in cattle: 20 cases
}

\section{Aline Rodrigues ${ }^{1}$ Raquel Rubia Rech ${ }^{2}$ Ricardo Rocha de Barros ${ }^{3}$ Rafael Almeida Fighera² ${ }^{2}$ Claudio Severo Lombardo de Barros ${ }^{4}$}

\section{RESUMO}

Num estudo retrospectivo de 1.071 necropsias de bovinos, foram encontrados 20 casos de babesiose cerebral confirmados pelo exame de esfregaços do córtex telencefálico. A maioria desses casos ocorreu no verão, em bovinos adultos de raças européias ou suas cruzas. Além dos sinais clínicos neurológicos, observou-se hemoglobinúria, anorexia, febre, taquicardia, taquipnéia e queda na produção de leite. O hemograma realizado em cinco bovinos afetados revelou acentuada anemia regenerativa; em média, 20\% dos eritrócitos estavam parasitados por Babesia bovis. $\mathrm{Na}$ necropsia de todos os casos, a substância cinzenta dos córtices telencefálico e cerebelar e dos núcleos da base era consistente e caracteristicamente róseo-cereja. Essa coloração devia-se ao seqüestro de eritrócitos nos capilares encefálicos. Nesses eritrócitos, podiam-se observar, tanto em esfregaços do córtex como em preparações histológicas do encéfalo, microorganismos com morfologia compatível com B. bovis. Outros achados de necropsia incluíam hemoglobinúria, rins vermelho-escuros, hepatoesplenomegalia, fígado vermelhoalaranjado, icterícia, hemorragias epicárdicas e endocárdicas e edema e congestão dos linfonodos mesentéricos.

Palavras-chave: Babesia bovis, babesiose cerebral, sistema nervoso central, doenças de bovinos, patologia.

\begin{abstract}
In a retrospective study carried out in 1,071 necropsies of cattle, 20 cases of cerebral babesiosis were found. All the cases were confirmed by examination of tissue smears from telencephalic cortex. Most of these cases occurred in the summer in adult cattle of European breeds and their crosses. Clinical signs included neurological disturbances, hemoglobinuria, anorexia, fever, tachycardia, tachypnea and drop in milk yield. Blood cell counts performed in five affected cattle revelead marked regenerative anemia with an average of $20 \%$ of Babesia bovis parasitized erythrocytes. At necropsy of all cases the gray matter of the telencephalic and cerebellar cortices and of the basal ganglia consistently had a typically pink-cherry discoloration due to sequestration of red blood cells in brain capillaries. Both in nervous tissue smears and in histological preparations, it was observed that the red blood cells that clogged the capillaries of the gray matter contained organisms with morphology compatible with $\boldsymbol{B}$. bovis. Other necropsy findings included red urine, dark-red kidneys, enlarged liver and spleen, red-orange discoloration of the liver, icterus, epicardial and endocardial hemorrhages, and congestion and edema of mesenteric lymph nodes.
\end{abstract}

Key words: Babesia bovis, cerebral babesiosis, central nervous system, diseases of cattle, pathology.

\footnotetext{
${ }^{1}$ Aluno do 11ำ semestre do Curso de Medicina Veterinária da Universidade Federal de Santa Maria (UFSM). Bolsista de Iniciação Científica do Conselho Nacional de Desenvolvimento Científico e Tecnológico (CNPq) junto ao Departamento de Patologia da UFSM.

${ }^{2}$ Médico Veterinário, aluno de doutorado no Programa de Pós-graduação em Medicina Veterinária (PPGMV), UFSM, área de concentração em Patologia Veterinária.

${ }^{3}$ Médico Veterinário, aluno de mestrado no PPGMV, UFSM, área de concentração em Patologia Veterinária.

${ }^{4}$ Médico Veterinário, PhD, Professor Titular do Departamento de Patologia, UFSM, 97105-900, Santa Maria, RS, Brasil. Emailclaudioslbarros@uol.com.br (autor para correspondência).
} 


\section{INTRODUÇÃO}

Infecções por Babesia spp. em bovinos são caracterizadas por febre, anemia, hemoglobinemia, hemoglobinúria e, em muitos casos, morte (EVERITT et al., 1986). A doença clínica é relacionada a ciclos repetidos de invasão e multiplicação dos protozoários em eritrócitos do hospedeiro, seguidos de lise eritrocitária e invasão de outros eritrócitos (de VOS \& POTGIETER, 1993). No Brasil, a babesiose bovina é causada por $\boldsymbol{B}$. bovis e B. bigemina, que são inoculadas no hospedeiro por um único vetor, o carrapato Boophilus microplus (FARIAS, 1995).

Tem sido observado que, na infecção por B. bovis em bovinos, ocorre seqüestro de eritrócitos parasitados nos capilares da substância cinzenta do encéfalo (ZLOTNIC, 1953; CALLOW \& McGAVIN, 1963; ROGERS, 1971; PATARROYO et al., 1982). Isso provoca eventos químicos e imunológicos que induzem uma manifestação clínica distinta, caracterizada por sinais neurológicos e conhecida como babesiose cerebral (CALLOW \& McGAVIN, 1963; KESSLER et al., 1983).

Com freqüência, casos de babesiose cerebral são confundidos com outras doenças do sistema nervoso central de bovinos, inclusive com a raiva. Este trabalho revisa os achados epidemiológicos, clínicos e patológicos da babesiose cerebral encontrados na necropsia de 20 bovinos. Tem como objetivo chamar a atenção para a importância dessa entidade no diagnóstico diferencial das doenças do sistema nervoso central de bovinos no Brasil, como parte do programa de vigilância da encefalopatia espongiforme bovina (BARROS, 2003).

\section{MATERIAL E MÉTODOS}

Foram revisados os protocolos de necropsias de bovinos dos arquivos do Departamento de Patologia da Universidade Federal de Santa Maria, realizadas no período 19992003 por docentes do departamento ou por veterinários de campo que enviaram material para diagnóstico. Desse material foram selecionados somente os casos em que o diagnóstico de babesiose cerebral havia sido confirmado por exame de esfregaços do córtex telencefálico (CALLOW \& McGAVIN, 1963) corados por panótico rápido. Em cinco dos 20 bovinos, havia dados do hemograma realizado em sangue colhido da jugular. Os dados epidemiológicos, clínicos, laboratoriais, de necropsia e histopatológicos desses casos foram avaliados.

\section{RESULTADOS}

Dos 1.071 protocolos de necropsia do período revisado, 20 tinham diagnóstico confirmado de babesiose cerebral . Treze desses casos ocorreram no verão, quatro na primavera, dois no inverno e um no outono. Os bovinos eram de raças européias (65\%) ou cruzas dessas raças (25\%); em dois casos (10\%) não constava a raça no protocolo de necropsia. Sessenta e cinco por cento (incluindo as cruzas) eram de exploração para corte e 35\% eram de produção leiteira. A idade dos animais variou de seis meses (um caso de um bezerro de tambo) a oito anos (média de três anos). Todos os animais apresentaram distúrbios neurológicos que incluíam incoordenação motora (6/20); opistótono, cegueira e tremores musculares (4/20); paralisia dos membros pélvicos e movimentos de pedalagem (3/20); pressão da cabeça contra objetos (3/20); andar em círculos e agressividade (1/20). Outros sinais clínicos observados foram hemoglobinúria, anorexia, febre, taquicardia, taquipnéia e queda na produção de leite. Dados do hemograma indicavam anemia regenerativa acentuada caracterizada por policromasia, anisocitose, corpúsculos de Howell-Jolly e metarrubricitemia. A média de eritrócitos parasitados foi de aproximadamente $20 \%$ (10\% a 44\%).

Na necropsia de todos os casos, a substância cinzenta dos córtices telencefálico e cerebelar e dos núcleos da base tinham uma cor róseo-cereja (Figura 1A). Embora essa alteração fosse bem marcada na substância cinzenta, era também levemente perceptível na substância branca. Nos esfregaços do córtex telencefálico, os capilares apareciam repletos de eritrócitos parasitados por organismos basofílicos, solitários ou pareados, de 2 $\mu \mathrm{m}$ de diâmetro (Figura 1B), aspectos compatíveis com Babesia bovis. Outros achados de necropsia presentes em todos os casos incluíam urina cor de vinho tinto (hemoglobinúria), rins vermelho-escuros, fígado vermelho-alaranjado, hepatoesplenomegalia, petéquias e equimoses no epicárdio do sulco coronário e no endocárdio ventricular esquerdo, edema e congestão dos linfonodos mesentéricos e embebição hemoglobínica nas serosas das vísceras gastrintestinais. Em cinco casos, foi relatada icterícia leve ou moderada e, em três, foi observado edema do mesentério. Na histologia, observou-se congestão vascular e edema perivascular e perineuronal no encéfalo, nefrose hemoglobinúrica, necrose hepática centrolobular e bilestase canalicular. Microorganismos morfologicamente compatíveis com $\boldsymbol{B}$. bovis eram visíveis na grande maioria dos eritrócitos seqüestrados nos capilares do encéfalo. Em nenhum caso observou-se trombose nos capilares ou hemorragias perivasculares. 


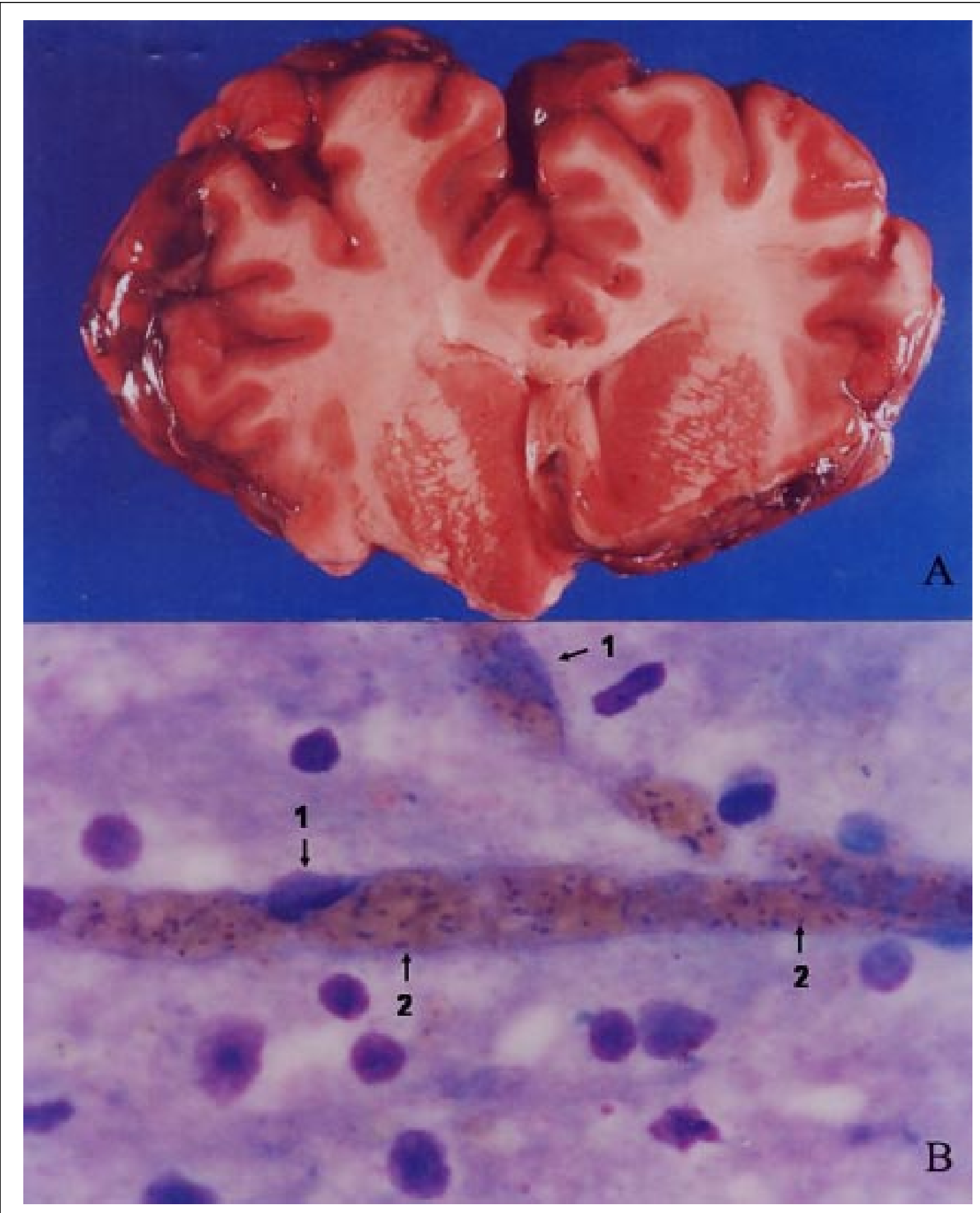

Figura 1 - Babesiose cerebral em bovinos causada por Babesia bovis (caso V-678-01). A. Corte transversal do cérebro de um bovino afetado mostrando a coloração róseo-cereja da substância cinzenta do córtex telencefálico e dos núcleos da base. Essa lesão, por si só, permite o diagnóstico, na necropsia, de babesiose cerebral causada por $\boldsymbol{B}$. bovis. B. Esfregaço do córtex telencefálico. Os capilares estão distendidos por eritrócitos parasitados por B. bovis. Os eritrócitos aparecem como massas amareloalaranjadas; 1, célula endotelial do capilar; 2 , B. bovis no interior de eritrócito. Ao redor do vaso podem ser vistas várias células não identificadas do tecido nervoso. Panótico rápido, obj. de imersão.

Ciência Rural, v.35, n.1, jan-fev, 2005. 


\section{DISCUSSÃO}

A ocorrência dos casos de babesiose cerebral aqui relatados concentrou-se nos meses de verão e afetou principalmente animais acima de um ano de idade, de áreas de instabilidade enzoótica para babesiose e seu vetor. Esse aspecto epidemiológico é descrito para a babesiose bovina no Rio Grande do Sul (FARIAS, 1995).

Os sinais neurológicos observados nos bovinos deste estudo são semelhantes aos descritos por outros autores (ZLOTNIC, 1953; ROGER, 1971; de VOS \& POTGIETER, 1993; VALLI, 1993). Para a realização do diagnóstico, esses sinais devem ser considerados junto com dados epidemiológicos e com outros sinais clínicos (anemia, hemoglobinemia, hemoglobinúria e icterícia). Os achados hematológicos descritos em cinco bovinos deste estudo são relacionados à anemia hemolítica (GAUNT, 2000) e devem também, se possível, ser incluídos no conjunto de dados para confirmação do diagnóstico clínico. Tem sido sugerido que, para o diagnóstico de babesiose por $\boldsymbol{B}$. bovis, o sangue deva ser colhido da orelha ou ponta da cauda porque a parasitemia no sangue circulante dos grandes vasos é baixa, raramente atingindo 5\% (VALLI, 1993); no entanto, nos cinco casos deste estudo em que o sangue foi colhido da jugular, a parasitemia detectada foi alta (10\%-44\%). Esses dados, embora limitados, sugerem que, pelo menos na doença aguda com manifestação neurológica, a parasitemia pode ser suficiente para permitir o diagnóstico em amostras de sangue colhidas na jugular.

Na necropsia, a babesiose cerebral pode ser confirmada pela lesão macroscópica característica, i.é, a coloração róseo-cereja da substância cinzenta do encéfalo. Essa alteração ocorre somente na infecção por B. bovis (CALLOW \& McGAVIN, 1963; de VOS \& POTGIETER, 1993) e por isso é um indicador preciso e importante para o diagnóstico definitivo já durante o exame macroscópico. Isso nem sempre é suficientemente enfatizado em textos de patologia veterinária. Essa lesão decorre do seqüestro de eritrócitos parasitados por $\boldsymbol{B}$. bovis nos capilares e vênulas do cérebro. Os eritrócitos parasitados exibem protuberâncias estelares da membrana plasmática que aparentemente medeiam a aderência dessas células ao endotélio dos capilares e seu seqüestro na microcirculação (EVERITT et al., 1986). A cor é mais intensa na substância cinzenta do que na substância branca, porque os capilares são mais numerosos na primeira e porque há mais eritrócitos parasitados em pequenos capilares (CALLOW \& McGAVIN, 1963). Após aderência de $\boldsymbol{B}$. bovis, ocorre ativação dos sistemas das cininas, da coagulação e do complemento (EVERITT et al., 1986) e é provável que esses eventos sejam responsáveis pelas alterações circulatórias que ocorrem no cérebro e pelos sinais clínicos neurológicos da babesiose cerebral. Microtromboses (PATARROYO et al., 1982) e hemorragias perivasculares (CALLOW \& McGAVIN, 1963) têm sido relatadas no cérebro de bovinos afetados pela forma cerebral da infecção por B. bovis. Nenhuma dessas alterações foi encontrada no encéfalo dos bovinos deste estudo; nossos dados morfológicos sugerem que a coagulação intravascular disseminada não faz parte da patogenia da babesiose cerebral como já havia sido apontado (de VOS \& POTGIETER, 1993).

A babesiose cerebral em bovinos pode ser comparada com a infecção por Plasmodium falciparum (malária) em humanos (SAMUELSON, 1999). Na forma cerebral da malária falcípara, também ocorre seqüestro de eritrócitos na microvasculatura do encéfalo induzindo alterações morfológicas e clínicas comparáveis às da babesiose cerebral em bovinos.

A lesão macroscópica do encéfalo descrita e ilustrada neste relato ocorre no cérebro de bovinos exclusivamente na infecção por $\boldsymbol{B}$. bovis e, portanto, seu achado na necropsia permite o diagnóstico definitivo dessa condição.

\section{REFERÊNCIAS BIBLIOGRÁFICAS}

BARROS, C.S.L. Procedimentos para o diagnóstico das doenças do sistema nervoso central de bovinos. Brasília: Ministério da Agricultura, Pecuária e Abastecimento, Departamento de Defesa Animal, 2003. 50p.

CALLOW, L.L.; McGAVIN, M.D. Cerebral babesiosis due to Babesia argentina. Australian Veterinary Journal, v.39, p.15-21, 1963.

De VOS, A.J.; POTGIETER, F.T. Bovine babesiosis. In: COETZER, J.A.W. et al. Infectious diseases of livestock with special reference to Southern Africa. Cape Town : Oxford University, 1993. V.1, cap.23, p.278-294.

EVERITT, J.I. et al. Experimental Babesia bovis infection in Holstein calves. Veterinary Pathology, v.23, p.556-562, 1986.

FARIAS, N.A.R. Diagnóstico e controle da tristeza parasitária bovina. Guaíba : Agropecuária, 1995. 80p.

GAUNT, S.D. Hemolytic anemias caused by blood rickettsial agents and protozoa. In: FELDMAN, B.F. et al. Schalm's veterinary hematology. 5.ed. Philadelphia : Lippincott Williams \& Wilkin, 2000. Cap.27, p.154-162.

KESSLER, R.H. et al. Babesiose cerebral por Babesia bovis (Babés 1888 Starcovici 1893) em bezerros no Estado de Mato Grosso do Sul. Pesquisa Agropecuária Brasileira, v.18, p.931-935, 1983.

Ciência Rural, v.35, n.1, jan-fev, 2005. 
PATARROYO, J.H. et al. Description of lesions in cattle in a natural outbreak of Babesia bovis infection in Brazil. Veterinary Parasitology, v.11, p.301-308, 1982.

ROGERS, R.J. Observations on the pathology of Babesia argentina infections in cattle. Australian Veterinary Journal, v.47, p.242-247, 1971.

SAMUELSON, J. Infectious diseases. In: COTRAN, R.S. et al.
Robbins pathologic basis of disease. 6.ed. Philadelphia : Saunders, 1999. Cap.9, p.389-391.

VALLI, V.E.O. The hematopoietic system. In: JUBB, K.V.F. et al. Pathology of domestic animals. 4.ed. San Diego : Academic, 1993. V.3, cap.2, p.101-265.

ZLOTNIC, L. Cerebral piroplasmosis in cattle. Veterinary Record, v.40, p.642-643, 1953 